\title{
Numerical and Experimental Analyses of Equal Channel Angular Processing of Pure Aluminum
}

\author{
W.H. El-Garaihy* \\ Mechanical Engineering Department, College of Engineering- Unizah, Qassim University, Saudi Arabia \\ Mechanical Engineering Department, Faculty of Engineering, Suez Canal University, Egypt \\ *Corresponding author: Email: W.Nasr@qu.edu.sa \\ DOI: $10.5185 /$ amlett.2020.061532
}

Nowadays, Equal Channel Angular Processing (ECAP) is one of the most appealing and potentially efficient Severe Plastic Deformation techniques (SPD) for fabricating Ultrafine Grained (UFG) and Nanostructured materials (NS) with sufficiently improved mechanical properties which has enabled this technique to be used in industrial applications. In this study, commercially pure aluminum was processed by ECAP through route A for up to 4 passes. A Finite Element (FE) analysis was carried out and compared to the experimental findings in order to investigate the effects of the geometric and the process' parameters on the plastic deformation behavior of the work-piece during the ECAP process. The number of passes was selected as an input factor, while hardness values and compressive properties were modeled as the response. The total imposed stresses and strain as a function of the number of passes were examined. The FE analysis were carried out, yielding favorable results, concurring perfectly with the experimental findings and the microstructural evolution.

\section{Introduction}

SPD is one of the most efficient top-down methods for the fabrication of UFG and NS materials [1-2]. In SPD processes, bulk billets are subjected to high plastic strains in order to obtain UFG materials [3]. UFG materials with average grain size lower than $\sim 1 \mu$ m possess a combination of superior strength and good ductility compared to their coarse-grained (CG) counterpart [4]. For CG materials, only a small percentage of atoms are positioned at or in the transitional vicinity of Grain boundaries (GBs). On the other hand, UFG materials have a large GBs area, which resulted in more atoms being located near GBs [5]. Accordingly, it is also well known that the NS and ultrafine grains can hinder the motion of dislocations' due to their pinning roles. Consequently, this improved significantly the mechanical properties of the sample [6-7]. Accordingly, the increased value of strength is obtained by applying higher stress in order to overcome the dislocation motion barrier and to move the dislocations. Hence, an inverse conjunction between the materials strength and the materials grain size is introduced as by the Hall-Petch equation [8-10].

Nowadays, many SPD processing process are available such as: ECAP, Accumulative Roll-Bonding (ARB), Twist Extrusion (TE) and High-Pressure Torsion (HPT) [1, 1117]. Among the different SPD techniques, ECAP is the most developed and promising SPD technique and has the potential to be used in industrial applications [11, 18-19]. During the ECAP process, the processed material is subjected to a highly-accumulated shear strain as a billet is expelled through a die with two channels, equal in cross section and intersecting at an die angle $\Phi$, with an angle of curvature $\Psi[\mathbf{7}, \mathbf{2 0 - 2 1}]$ as shown in Fig. 1. The ECAP method is generally characterized as a continuous processing technique, as the sample can be extruded repeatedly through a number of passes till the homogeneity in microstructure and mechanical properties are attained [22]. The main superiority of ECAP processing is that ECAP leads to a high degree of grain refinement coupled with the creation of High-Angle Grain Boundaries (HAGBs) [23]. On the other hand, regardless of the kind of processing materials, the ECAP process results in inhomogeneous deformation of the sample. The deformation inhomogeneity shows a difference in the microstructure and the mechanical properties of the processed materials [4].

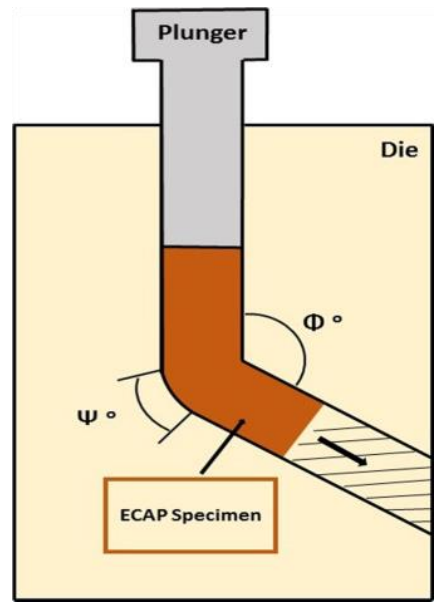

Fig. 1. Schematic of the ECAP die setup [17]. 


\section{Advanced Materials Letters www. vbripress.com/aml}

The ECAP technique has been broadly investigated and analyzed using many different metals and their alloys [24-31]. The purpose of this study is to provide a more detailed mapping of the ECAP process through numerical modeling to study the effectively induced stress-strain behaviors and their distribution after multiple passes of ECAP processing of commercially pure aluminum. Validation of the numerical model is carried out by investigating the hardness distribution across the sample's transverse section and microstructural observations after deformation.

\section{Mathematical and numerical modeling}

FE analysis was carried out to display the imposed strain distribution and stress distribution during ECAP processing. In addition, the $\mathrm{FE}$ analysis was compared to the experimental geometries in order to investigate the effects of the geometric, material and process parameters on the plastic deformation behavior of the pure aluminum billet during the ECAP process.

To simulate the ECAP process, the cold forming extrusion module was used. The model consisted of the plunger, ECAP 2-halves die, and the ECAPed rods. For clarity and improved visualization, all parts were invisible apart from the billet during simulation. The 2-halves die, plunger and billet were modeled as rigid body made of an imaginary non-formable material. Pure aluminum was selected from the built-in library as the material of the work-piece. The mechanical and thermal properties were pre-described. Furthermore, hexahedral mesh which is typically used in computational modeling of 3-Dimension (3D) regular shapes was used with mesh size of $0.5 \mathrm{~mm}$ which yielded a total number of nodes of 9500 to 15000 elements depending on specimen's degree of distortion which increased in each pass as shown in Fig. 2. The ECAPed material was modeled as an isotropic linear elastic and strain hardenable rigid plastic material. Tracked elements were located at the plane in the middle of the specimen at the edge where max strain occurs and at the center where SPD has the lowest effect. Ram speed was adopted to be $0.05 \mathrm{~mm} / \mathrm{s}$. Coulomb friction model was used with die friction factor 0.05 .

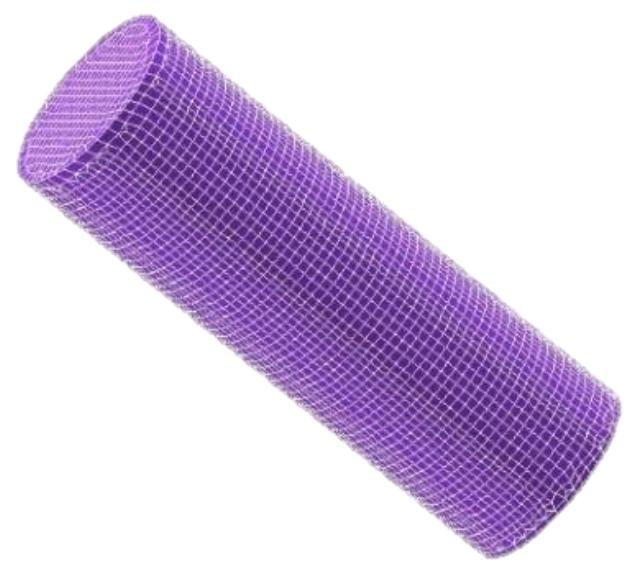

Fig. 2. The used hexahedral mesh type.

\section{Experimental procedure}

Rods of commercially pure aluminum were investigated. The commercially pure aluminum used in this work was received in the form of circular rods with the chemical composition as listed in Table 1. The aluminum rods were processed through ECAP for up to 4 passes of route A at ambient temperature on a hydraulic press of 100 -ton. The aluminum rods were lubricated using graphite-based lubricant and pressed into the ECAP die with a ram speed of $0.05 \mathrm{~mm} / \mathrm{s}$. Prior to ECAP, the aluminum rods were annealed at $120{ }^{\circ} \mathrm{C}$ for 1 hour for homogenization of the microstructure. To carry out the ECAP process, the asannealed rods were machined into cylindrical specimens with length of $70 \mathrm{~mm}$ and diameter of $15 \mathrm{~mm}$. The initial average grain size in the annealed condition was $85 \mu \mathrm{m}$. The ECAP die was fabricated from high strength steel (W302) with the die angles $\varphi=120^{\circ}$ and die curvature angle of $\psi=10^{\circ}$.

Table 1. Chemical composition of the commercially pure aluminum used in this work (in wt. \%)

\begin{tabular}{lcccccc}
\hline Element & $\mathrm{Fe}$ & $\mathrm{Si}$ & $\mathrm{Cu}$ & $\mathrm{Mg}$ & $\mathrm{Mn}$ & $\mathrm{Al}$ \\
\hline $\begin{array}{l}\text { Weight } \\
\text { percent }\end{array}$ & 0.45 & 0.12 & 0.16 & 0.06 & 0.07 & Balance \\
\hline
\end{tabular}

After ECAP processing, the aluminum rods were polished to a mirror like shape. Vicker's micro-hardness (Hv) values were measured from the ECAPed rods' center to their peripheries on the rods' longitudinal section using Qualitest digital micro-hardness tester using an applied load of $1 \mathrm{~kg}$ for $15 \mathrm{~s}$. The average of at least 5 individual hardness measurements was taken as the hardness of the appropriate specimen.

Microstructural aspects of ECAPed specimens were characterized by Optical Microscopy (OM). Specimens were cut from the as-annealed and ECAPed samples, parallel and perpendicular to the ECAP pressing direction. A high-precision cutter was utilized to cut the rods. The samples were prepared according to standard metallographic procedures and were etched by Flick's reagent (distilled water $89.88 \%$, hydrochloric acid $5.47 \%$, and hydrofluoric acid $4.65 \%$ ) for 9 seconds.

\section{Results and discussion}

\section{Numerical analysis}

Fig. 3, shows the effective stresses and distribution contours and a sectional view of the stresses distribution for the ECAPed specimens processed via 1, and 4 passes of route A. Similar displays of the strains distribution are displayed in Fig. 4. The plunger and die have been removed for better visualization and depiction. As shown in Fig. 3, the maximum stresses were displayed at the corner and peripheral areas compared to the central areas. This could be explained as due to the contact of the specimen with the applied pushing force from the plunger, which yielded comparably higher $\mathrm{Hv}$ values at the top part. Fig. 3a, b shows the processed rod after processing via 1-pass (1-A), 


\section{Advanced Materials Letters www. vbripress.com/aml}

where the maximum stress experienced was in the range of $84 \mathrm{MPa}$ which occurred in the peripheral regions. On the other hand, the central region recorded lower stresses of 10 MPA. As ECAP straining continues for multiple passes, more strain was induced and hence, higher loads were needed to extrude the processed material and accordingly, the effective stresses increased. From Fig. 3c, $d$ it is clear that, increasing the processing passes up-to 4-passes of route $\mathrm{A}$ (4-A) led to increasing the maximum stress up- to $121 \mathrm{MPa}$ in the top edges. While the central regions recorded lower stresses in the range of $28 \mathrm{MPa}$. Moreover, it could be observed that the top ends of the rods experienced higher stresses compared to bottom regions as a result of the direct contact between the top ends with the plunger. Additionally, from Fig. 4 it is clear that processing via 1-A experienced effective strain of about 0.75 . Increasing the ECAP passes up-to 4-A resulted in increasing the maximum strain up to- 4 which depicted at the upper edge of the sample while the average imposed strain reached 3.25 at the peripheral regions and the lower part of the specimen displayed a strain value of 1.25.

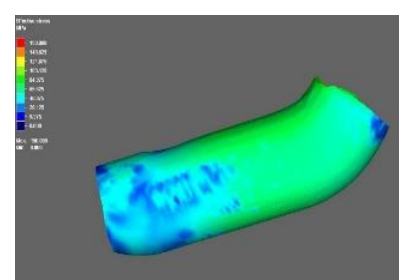

a

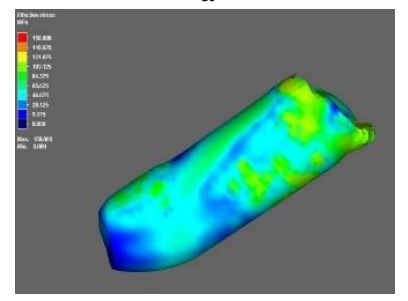

C

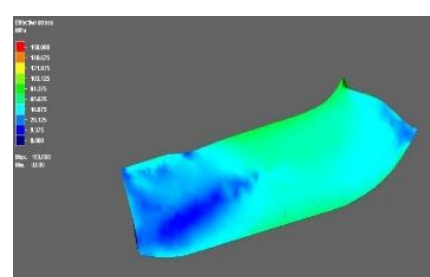

b

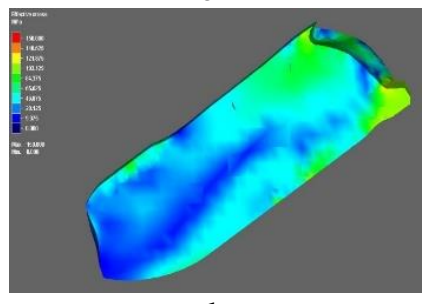

d
Fig. 3. Effective stresses distribution in ECAPed samples (a, c), sectional view of the stress distribution $(b, d)$ after processing via $(a, b)$ 1-Pass (c, d) 4-A.

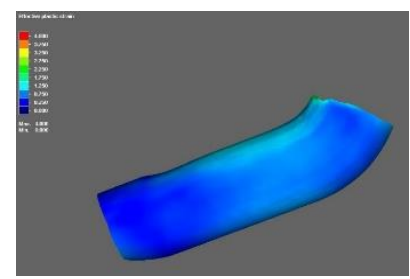

a

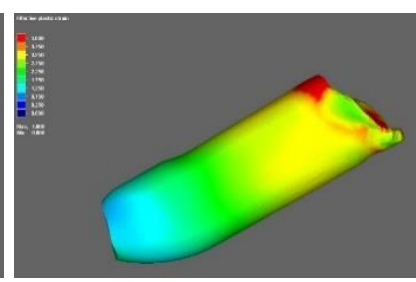

b
Fig. 4. Effective strain distribution in ECAPed samples after processing via (a) 1-Pass (b) 4-A.

\section{Hardness evolution}

The average microhardness value of the as-annealed aluminum rods was $35 \mathrm{Hv}$. The hardness variation along the cross-section in terms of the distance from the ECAPed rod center are shown in Fig. 5 for the aluminum rods processed through 1-A up to 4-A. In addition, the average Vickers micro-hardness of the ECAPed rods processed through 1$\mathrm{A}$, and 4-A near the edges and at central region are shown in Table 2. As shown in Fig. 5, it is clear that processing via ECAP resulted in increasing the Hv-values. A similar trend was noticed for the aluminium rod processed via 2-A. In addition, further straining through ECAP up-to 4-A showed increasing the Hv-values due to strain hardening which caused the predominant effect of high dislocation density.

Table 2. Average Values of Hv-values measured at centre and peripheries.

\begin{tabular}{c|c|c|c}
\hline \multirow{2}{*}{ Location } & \multicolumn{3}{|c}{ Vickers micro-hardness average values (Hv) } \\
\cline { 2 - 4 } & As-Annealed & $\mathbf{1 - A}$ & 4-A \\
\hline centre & 35 & 50 & 60.5 \\
\cline { 3 - 4 } edge & 35 & 63 & 73 \\
\hline
\end{tabular}

Processing through 1-A revealed a significant increase in the $\mathrm{Hv}$-values at the central regions, in which the $\mathrm{Hv}$-values increased to $\mathrm{Hv}=50$ indicating an increase of $43 \%$ compared to Hv-value of the as-annealed specimen. On the other hand, the peripheral areas showed increasing the Hv-value by $80 \%$ compared to the as-annealed specimen. This difference in the Hv-values between the central and peripheral areas can be explained by the difference between the stress and strain imposed to the central and edges areas which come in agree with the FE analysis shown in Fig. 3a, b. Continuous straining via ECAP up to 4-A showed further increase in the $\mathrm{Hv}$ value by $21,15.8 \%$ in the central and peripheral regions, respectively compared to the ECAPed sample processed by 1-A. This agrees with the higher simulated effective strain imposed to the sample 4-A compared to the ECAPed sample processed via 1-A as shown in Fig. 4. Accordingly, superior $\mathrm{Hv}$-values were recorded at the peripheral regions surpassing that of the central ones, this could be linked to the high friction induced at the processing die-rods interface, which resulted in the increased strain hardening effect at the peripheries, surpassing that of the center.

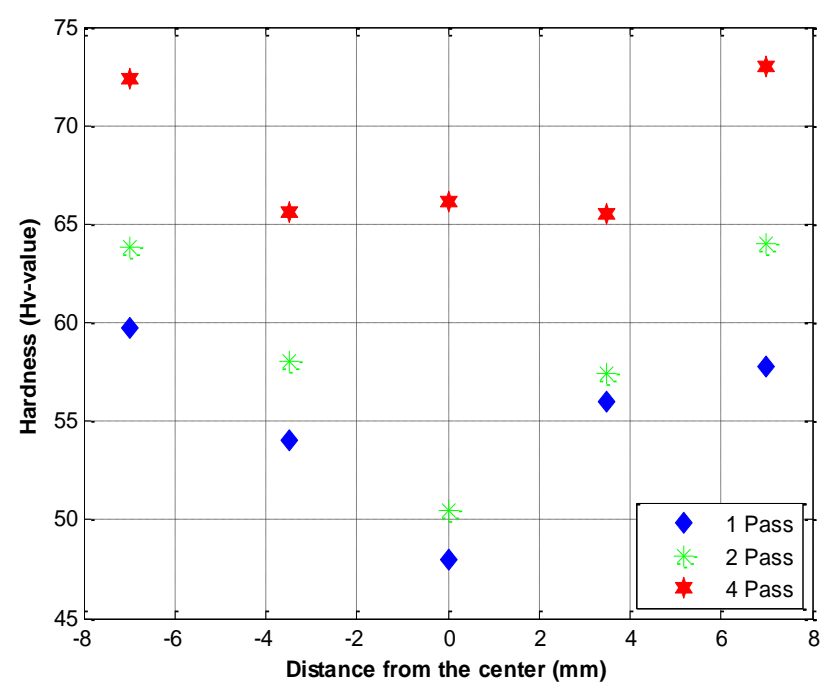

Fig. 5. Distribution of the hardness values across the rod transverse crosssection for 1, 2, and 4-A passes. 


\section{Advanced Materials Letters www. vbripress.com/aml}

\section{Microstructural evolution}

The average grains size of the as-annealed rod was $85 \mu \mathrm{m}$ as shown in Fig. 6. The OM micrograph showed that the as-annealed rod had relatively coarse grains. The microstructure of the ECAPed samples processed through 1-A and 4-A at the central and peripheral regions are displayed in Fig. 7. In addition, the samples' average grain sizes at the sample's center and near the periphery are listed in Table 3. From Fig. 7 the bi-modal grain structure is observable, where coarse grains were found coupled with finer ones after processing via 1-A (Fig. 7a, b), this remark was still observed after 4-A (Fig. 7c, d). This difference in grains size between the coarse and fine grains decreased with higher straining, which confirms that continuous processing via ECAP makes the ECAPed sample's grain size more uniformly distributed which agrees with [25].

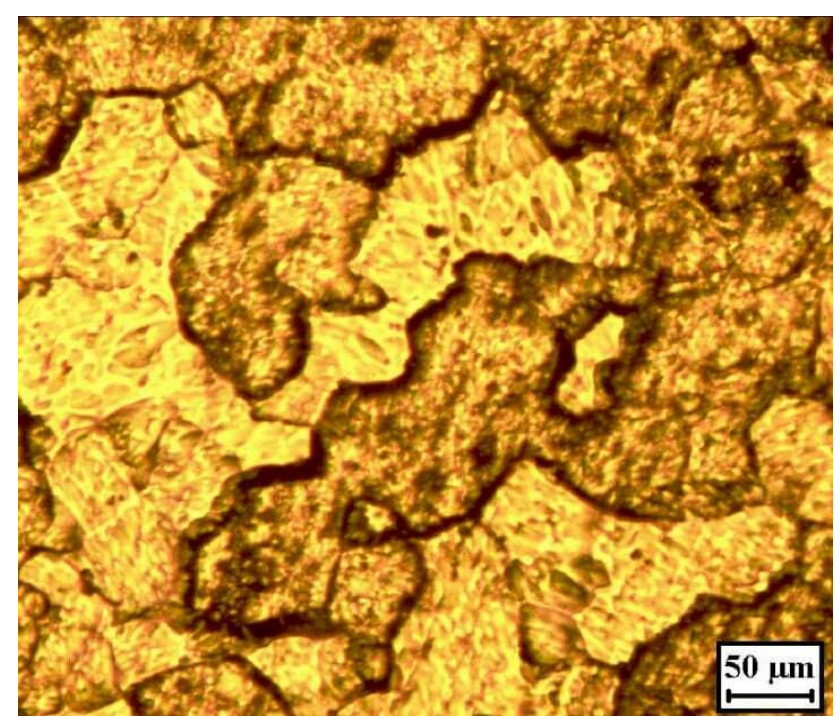

Fig. 6. OM micrographs of as-annealed aluminum rod.

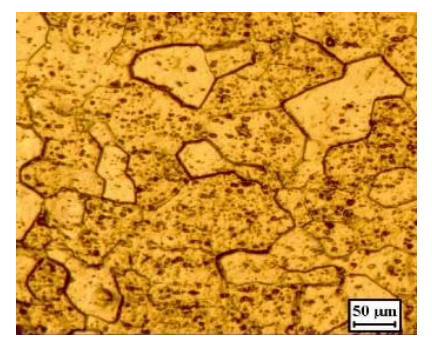

a

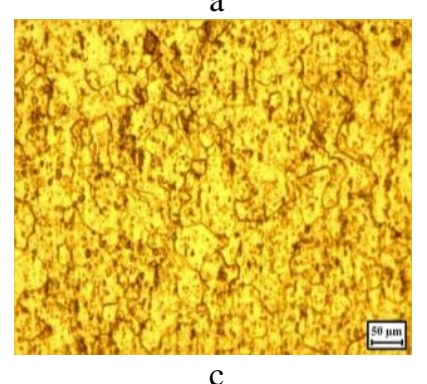

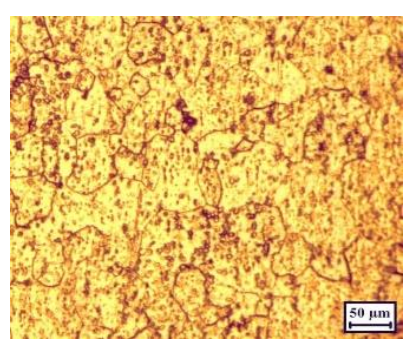

b

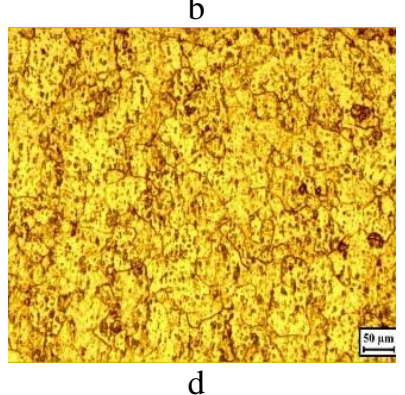

Fig. 7. OM micrographs of pure aluminum at (a, c) central and (b, d) peripheral regions processed using $\operatorname{ECAP}$ via $(\mathrm{a}, \mathrm{b}) 1-\mathrm{A}$, and (c, d) 4-A.
From Fig. 7 it can be concluded that the grain sizes of the central regions of ECAPed aluminum specimens were refined when compared to the as-annealed condition by 35 , and $59 \%$, after processing through 1 -A, and 4-A passes, respectively. Additionally, the peripheral regions of the ECAPed rods showed further refinement compared to the central regions. The grain sizes near the edges experienced refinement by 46 , and $69 \%$, after processing via $1-\mathrm{A}$, and $4-\mathrm{A}$ passes respectively, when compared with the as-annealed condition. This result correlates to the FE analysis shown in Fig. 3 and Fig. 4. Accordingly, higher stresses and strain imposed more at the peripheral regions compared to the central regions leads to more refinement.

Table 3. Average grain size for the processed and as-annealed aluminium rods.

\begin{tabular}{c|c|c|c}
\hline \multirow{2}{*}{ Location } & \multicolumn{3}{|c}{ Average Grain Size $(\boldsymbol{\mu m})$} \\
\cline { 2 - 4 } & As-annealed & 1-A & 4-A \\
\hline Centre & 85 & 55 & 35 \\
\hline Edge & 85 & 46 & 26 \\
\hline
\end{tabular}

\section{Conclusions}

This work was undertaken to validate the deformation capabilities of ECAP process through a combination of numerical and experimental analysis. The effective stress and strain induced as a result of ECAP deformation and the evolution of hardness and grains size on commercially pure aluminum is outlined. The following can be concluded:

1. Findings of the FE analysis showed that the strain induced is a function of the number of ECAP passes, where straining via 1 -A induces max strain of 0.75 compared to 4 induced by $4-\mathrm{A}$.

2. The maximum strain was recorded at the upper edges and peripheral regions of the samples, while the minimum strain occurred at the lower part of the samples and at the central regions.

3. The $\mathrm{Hv}$ of the processed rods increases by 72.75 and $60.5 \%$ after the ECAP process via $4-\mathrm{A}$ at the peripheries and center respectively, compared to the as-annealed condition.

4. Augmenting the intensity of plastic straining through $4-A$ resulted in grain size reduction by 59 , and $69 \%$ at the peripheries and center respectively, compared to the as-annealed condition.

5. Further studies are needed to produce a comprehensive structural analysis using TEM/EBSD to further understand the influence of the ECAP imposed heterogeneous strain on the structural evolution of the ECAPed samples.

\section{Acknowledgements}

The author of this work would like to acknowledge the College of Engineering-Unaizah, Qassim University for granting the research fund for this project. Gratitude is also extended to the Material Testing Laboratories at the Mechanical Engineering department, College of Engineering-Unaizah, for the use of processing and testing equipment. 


\section{Advanced Materials Letters www. vbripress.com/aml}

\section{Keywords}

ECAP, severe plastic deformation, ultrafine grained materials, finite element analysis.

Received: 29 October 2019

Revised: 23 December 2019

Accepted: 30 December 2019

\section{References}

1. Ebrahimi, M.; Attarilar, S.; Shaeri, M.H.; Gode, C.; Armoon, H.; Djavanroodi, F.; Archives of Civil and Mechanical Engineering, 2019, 19,842 .

2. Cabibbo, M.; Metals, 2018, 962, 1.

3. Priela, E.; Mittelman, B.; Trabelsi, N.; Cohen, Y.; Koptiar, Y.; Padan, R.; Journal of Materials Processing Tech., 2019, 264, 469.

4. Lee, H.H.; Kim, H.; Jung, K.C.; Seo, S.; Lee, J.K.; Park, H.L.; Park, K.T.; Kim, H.S.; J. of Materials Processing Technology, 2018, 259, 305.

5. Shahriyari, F.; Shaeri, M.H.; Bavarsiha, F.; Noghani, M.T.; Materials Science \& Engineering A, 2019, 765, 1.

6. Liang, N.; Zhao, Y.; Li, Y.; Topping, T.; Zhu, Y.; Valiev, R. Z. Lavernia, E.J.; J. Mater. Sci., 2018, 53, 13173.

7. Shaeri, M.H.; Shaeri, M.; Salehi, M.T.; Seyyedein, S.H.; Abutalebi, M.R.; Progress in Natural Science: Materials International, 2015, 25, 159.

8. Valiev, R.Z.; Langdon, T.G.; Progress in Materials Science, 2006, 51,881 .

9. Chuvil'deev, V.N.; Nokhrin, A.V.; Myshlyaev, M.M.; Kopylov, V.I.; Lopatin, Y.G.; Melekhin, N.V.; Piskunov, A.V.; Bobrov, A. A.; Pirozhnikova, O.E.; Russian Metallurgy (Metally), 2018, 5, 487.

10. Chuvil'deev, V.N.; Nokhrin, A.V.; Myshlyaev, M.M.; Kopylov, V.I.; Lopatin, Y.G.; Melekhin, N.V.; Piskunov, A.V.; Bobrov, A. A.; Pirozhnikova, O.E.; Russian Metallurgy (Metally), 2018, 1, 71.

11. Suresh, M.; Sharma, A.; More, A.M.; Kalsar, R.; Bisht, A.; Nayan, N.; Suwas, S.; Journal of Alloys and Compounds, 2019, 785, 972.

12. Lia, Q.; Jiao, X.; Materials Science \& Engineering A, 2018, 733, 179.

13. Ghazani, M. S.; Fardi-Ilkhchy, A.; Binesh, B.; Trans Indian Inst Met, 2018.

14. Poovazhagan, L.; Ruthran, P.; Sreyas, S.; Thamizharasan, A.; Thejas, S.; Advances in Materials and Metallurgy, 2019, 29.

15. Latypov, M.I.; Lee, M.G.; Beygelzimer, Y.; Prilepo, D.; Gusar, Y.; Kim, H.S.; Metallurgical and Materials Transactions A, 2016, 47A, 1248.

16. El-Garaihy, W.H.; El-sayed M. A. Rassoul, Alaskari, A.M.; Alateyah, A.I.; Oraby, S.E.; SAE International Journal of Materials and Manufacturing, 2018, 11,1.

17. El-Garaihy, W.H.; Alaskari, A. M.; Ameshaiei, E.A.; Oraby, S.E.; Advanced Materials Letters, 2016, 8, 620.

18. Manjunath, G.K.; Kumar, Preetham G.V.; Bhat, K.U.; Huilgol, P.; Journal of Materials Engineering and Performance, 2018, 27, 5644.

19. Chinababu1, M.; Gudimetla, K.; Sivaprasad, K.; Ravisankar, B.; Materials Today: Proceedings, 2018, 5, 8241..

20. Shaeri, M.; Karimi Taheri K.; Karimi Taheri, A'; Shaeri, M.H.; Journal of Materials Engineering and Performance, 2019, 28, 5207.

21. Ma, M.; Li, Z.; Qiu, W.; Xiao, Z.; Zhao, Z.; Jiang, Y.; Journal of Alloys and Compounds, 2019, 788, 50.

22. Kunčická, L.; Kocich, R.; Ryukhtin, V.; Cullend, J.C.T.; Lavery, N.P.; Materials Characterization, 2019, 152, 94.

23. Manjunath, G. K.; Bhat, K. U.; Preetham Kumar, G. V.; Metallography, Microstructure, and Analysis, 2018, 7, 77.

24. Zhao, J.; Zhang, C.H.; Xu, C.B.; Journal of Mechanical Science and Technology, 2019, 3, 783 .

25. Fereshteh-Saniee1, F.; Asgari1, M.; Fakha, N.; Appl. Phys. A, 2016, 122.

26. Wang, H.; Ban, C.; Zhao, N.; Zhu, Q.; Cui, J.; Materials Science and Engineering A, 2019, 751, 246.

27. Yun-Xiang Tong, Yu Wang, Zhi-Min Qian, Dian-Tao Zhang, Li Li, Yu-Feng Zheng, Acta Metallurgica Sinica (English Letters), 2018, 31, 1084.

28. Arun, M.S.; Chakkingal, U.; Materials Science and Engineering A, 2019, 754, 659 .
29. Torabi, H.; Samadpour, F.; Faraji, G.; Masoumi, A.; Journal of Materials Engineering and Performance, 2019, 28, 5586.

30. Wang, L.; Wang, Y.; Zhilyaev, A.P.; Korznikov, A.V.; Li, S.; Korznikova, E.; Langdon, T.G.; J. Mater Sci., 2014, 49, 6640.

31. Tong, Y.X.; Hu, K.P.; Chen, F.; Tian, B.; Li, L.; Zheng, Y.F.; Intermetallics, 2017, 85, 163.

32. Chiu, C.; Huang, S.J.; Chou, T.Y.; Rabkin, E.; Journal of Alloys and Compounds, 2018, 743, 437. 